\title{
Coordenação pedagógica e corpo docente: a importância da formação continuada
}

\section{Resumo}

$\mathrm{Na}$ atual sociedade há facilidade de se obter, através de diversos meios de informação, em particular a Internet, notícias, dados econômicos e sociais de todo o mundo em tempo real. Faz-se necessário refletir sobre a formação dos cidadãos e, em particular, qual o papel da escola nesta sociedade e, por conseguinte qual o papel do professor nesse contexto.

Neste artigo, analisamos a formação de professores como um elemento essencial nesta sociedade de informação e o papel da coordenação pedagógica na concretização do projeto educacional e na formação continuada do corpo docente.

\section{Abstract}

In the current society it is easy to obtain news, economical and social data of everyone in real time through several means of information, mainly the Internet. It is necessary to think about the citizens' formation, especially, which role education takes in this society and therefore what role the teacher in this context.

In this article, we looked the teachers' formation as an essential element in this society of information and the role of the pedagogical coordination in the concretion of the educational project and in the continued formation of the faculty.
Palavras-chave: Sociedade de informação, formação de professores, papel da escola na sociedade, formação continuada, coordenação pedagógica.

Keywords: Information society, teacher training, school's role in society, continuing education, education supervision.

\section{Apresentação}

A educação brasileira, desde a educação básica até o ensino superior, tem sido objeto de grandes preocupações e discussões, seja por educadores, estudantes ou políticos; preocupações estas que revelam a necessidade de se ter profissionais capacitados para a tarefa social de educar.

As mudanças exigidas pelas reformas educacionais, motivadas pelas mudanças sociais, incidem também, como não poderiam deixar de ser, na formação dos profissionais da educação. O aprendizado contínuo é uma exigência dos dias atuais, faz-se necessário desenvolver a competência de "aprender a aprender e continuar aprendendo" durante toda a vida profissional. Essa competência é exigida não só para os alunos da educação básica, mas para todos os profissionais, todas aquelas pessoas que estão inseridas no mundo do trabalho.

\footnotetext{
${ }^{1}$ Marcos Roberto Celestino - Doutor e Mestre em Educação em Matemática - PUC/SP. Especialista em Gestão Escolar - UNICID/SP. Bacharel e Licenciado em Matemática - Universidade Presbiteriana Mackenzie - SP.

Email: mrcelestino@hotmail.com
} 
A Lei de Diretrizes e Bases da Educação Nacional (LDB - 9.394/96) reflete os anseios de nossa sociedade a qual está impulsionada pelas demandas de profissionais com uma formação que ao mesmo tempo deve analítica e crítica; demandas advindas do mundo globalizado em que a informação se encontra disponível e acessível a todos, porém essas informações necessitam ser retrabalhadas por todos os profissionais a fim de se tornarem conhecimento, uma vez que a informação recebe o status de conhecimento quando a mesma torna-se significativa para o indivíduo. Frade (2002) adverte que:

[...] um novo modelo de cidadania deve ir além da esfera da informação, incorporando a capacidade de interpretação da realidade e construção de sentido por parte dos indivíduos. O que importa na formação dos cidadãos, sob essa perspectiva, é que sejam capazes de ser construtores de significados (FRADE, 2002 apud SILVA et al., 2005, pág.30)

Dessa forma a escola continuará desempenhando um importante papel na sociedade, pois atendendo às demandas do mundo atual, deverá construir um projeto pedagógico que viabilize a formação de cidadãos aptos a construírem significados às informações que acessa e o professor, mediador dessa formação também deverá inserir-se nesse contexto.

É necessário refletir sobre o papel do professor na sociedade moderna e de que forma se deve dar essa formação, na qual a articulação entre a técnica, o conhecimento e a análise crítica devem ser elementos presentes e imbricados; com vistas a formar professores que sejam formadores de cidadãos aptos a coletar informações de diversas fontes e analisá-las de forma crítica e eficaz.

A escola é o local privilegiado para a formação continuada, processo que possibilita ao professor continuar aprendendo enquanto exerce seu ofício. Nesse contexto a Coordenação Pedagógica desempenha uma função importante na formação continuada dos professores e de liderança intrínseca, pois a mesma deve exercer influencia e estimular inovações nos projetos escolares, bem como contribuir para a formação continuada do corpo docente. Esse último aspecto é evidenciado pelas ações coordenadas a fim de dirimir fraquezas e valorizar habilidades e competências imprescindíveis ao educador.

O tema de nosso artigo: Coordenação pedagógica e corpo docente - a importância da formação continuada, está inserido nesse contexto. E o objetivo de nosso trabalho é apresentar um panorama sobre as demandas atuais para a formação continuada dos docentes e o papel da coordenação pedagógica nessa formação.

É notório que o assunto é amplo, mas analisaremos aspectos relevantes coletados durante a revisão de literatura de autores como Nóvoa, Perrenoud e Tardif, evidentemente sem a pretensão de esgotar o assunto ou efetuar um Estado da Arte.

Nossas motivações foram advindas da análise de entrevista com duas coordenadoras pedagógicas, uma atuante na rede pública e outra na rede particular de ensino, que dissertaram sobre a importância da formação continuada do professor e o papel do coordenador pedagógico nessa formação. Após realização das entrevistas levantamos os aspectos que julgamos mais relevantes e analisamos de que maneira pesquisadores/ educadores vêem a formação docente, quer formação inicial ou continuada, e o papel da coordenação pedagógica na formação continuada.

Esse artigo está divido da seguinte maneira:

No Tópico 2 - A sociedade do conhecimento e as novas demandas apresentamos os aspectos relevantes encontrados na Lei de Diretrizes e Bases da Educação Nacional a respeito da formação continuada.

No Tópico 3 - Formação Docente dissertamos a respeito da formação requerida 
na sociedade atual, formação esta científica que é analítica e crítica e descrevemos, nos subitens as características desejáveis de serem identificadas no professor, bem como seu papel no processo de ensino-aprendizagem e, consequentemente, sua atuação em sala de aula.

No Tópico 4-A Coordenação Pedagógica - projeto educacional e formação de professores - apresentamos uma reflexão a respeito da atuação da Coordenação Pedagógica na formação continuada, a atitude de liderança que essa coordenação deve desempenhar e o estímulo que deve propiciar à reflexão da prática docente.

Em seguida apresentamos as considerações finais, descrevendo de que maneira a docente e a Coordenação Pedagógica podem e devem estar comprometidos e promover ações conjuntas com vistas ao aprimoramento profissional mediante a promoção da formação continuada.

\section{A sociedade do conhecimento e as} novas demandas

A Lei de Diretrizes e Bases da Educação Nacional (LDB), lei $n^{\circ}$ 9.394/96 (LDB), em consonância com a demanda do mundo atual, afirma que os sistemas de ensino deverão promover a valorização dos profissionais da educação, assegurando-lhes "aperfeiçoamento profissional continuado inclusive com licenciamento periódico remunerado para esse fim" (artigo 67 - inciso II) e "período reservado a estudos, planejamento e avaliação, incluído na carga de trabalho" (artigo 67 - inciso V).

A reforma educacional promovida no Brasil exige um novo professor. São necessárias novas competências e novos conhecimentos e os professores não foram preparados para isso. Algum tempo atrás, na educação básica, não havia a preocupação de realizar um trabalho de forma interdisciplinar e contextualizado, $\log o$, muitos dos professores atuais não vivenciaram como alunos esse contexto, nem mesmo em sua formação profissional. Hoje sabemos quão importante para a formação do professor é experimentar situações de aprendizagem que depois, como professor, deverá propiciar aos seus alunos. Torna-se um desafio ao professor promover o desenvolvimento daquilo que não teve oportunidade de desenvolver.

A LDB apresenta a necessidade de mudanças nas incumbências e, portanto, no perfil do professor e evidencia a necessidade de os profissionais e as instituições serem flexíveis para poder acompanhá-las. Logo, faz-se necessário rever a formação inicial dos professores e promover atualização dos projetos pedagógicos nas escolas e estimular a formação continuada dos professores em exercício a fim de atender às novas demandas. Estamos, portanto, no âmbito da formação continuada.

Diante desse contexto, realizamos uma entrevista com duas Coordenadoras Pedagógicas (CP) - uma atuante na rede particular e outra na rede pública de ensino. Nosso objetivo foi de verificar como essas profissionais entendem a formação continuada e o papel do Coordenador Pedagógico nessa formação.

$\mathrm{Na}$ entrevista abordamos os seguintes aspectos: (I) A relevância da formação continuada (II) $\mathrm{O}$ papel do coordenador pedagógico na formação continuada (III) Obstáculos encontrados para desempenhar sua função - com vistas ao papel de formador.

A seguir apresentamos um quadro que destaca os principais pontos dessa entrevista. 


\begin{tabular}{|c|c|}
\hline Coordenadora 1 & Coordenadora 2 \\
\hline $\begin{array}{l}\text { Idade: } 58 \text { anos } \\
\text { Formação: } \\
\text { - Licenciatura Plena em Letras } \\
\text { (conclusão: 1972) } \\
\quad \text { - Complementação Pedagógica com } \\
\text { Habilitação em Direção e Supervisão } \\
\quad \text { Escolar (conclusão:1995) } \\
\text { Atuação no magistério: } 40 \text { anos } \\
\text { Atuação como CP: } 13 \text { anos } \\
\text { (rede particular) }\end{array}$ & $\begin{array}{l}\text { Idade: } 49 \text { anos } \\
\text { Formação: } \\
\quad \text { - Biologia (conclusão:1984) } \\
\text { - Psicopedagogia (conclusão: 1999) } \\
\text { - Pedagogia com Habilitação em Direção, } \\
\quad \text { Coordenação Pedagógica e Supervisão Escolar } \\
\text { (conclusão:1995) } \\
\text { Atuação no magistério: } 27 \text { anos } \\
\text { Atuação como CP: } 05 \text { anos } \\
\text { (rede pública - SME/SP) }\end{array}$ \\
\hline \multicolumn{2}{|l|}{ (I) A relevância da formação continuada } \\
\hline $\begin{array}{l}\text { - As constantes mudanças sociais, impulsionadas } \\
\text { pelo avanço científico e tecnológico, traz dúvidas, } \\
\text { contradições e um número incalculável de } \\
\text { informações, o que a torna cada vez mais } \\
\text { exigente. Nesse panorama de dúvidas e incertezas } \\
\text { encontra-se a atividade docente que também é } \\
\text { influenciada por esse cenário, implicando em um } \\
\text { processo de mudança na formação do professor. } \\
\text { - A reflexão crítica permanente que deve orientar a } \\
\text { formação continuada dos professores em busca da } \\
\text { transformação de sua prática educativa. } \\
\text { - A formação continuada dos professores deve } \\
\text { levá-los à apropriação dos saberes rumo à } \\
\text { autonomia e levar a uma prática reflexiva, } \\
\text { abrangendo a vida cotidiana da escola e os saberes } \\
\text { derivados da experiência docente. } \\
\text { - São indicativos para essa formação: o estudo } \\
\text { c o mp p rtilha do, o pla nej a m e nto e o } \\
\text { desenvolvimento de ações conjuntas. } \\
\text { - Os professores deverão reconstruir suas práticas } \\
\text { - a legislação vigente é bastante significativa, } \\
\text { pois, reconhece e obriga a se criar e desenvolver } \\
\text { programas de formação inicial e continuada para } \\
\text { os docentes. } \\
\text { - O professor hoje tem que dar conta das } \\
\text { demandas da sociedade e além de sua formação } \\
\text { inicial, muitas vezes, insuficiente, necessita de } \\
\text { uma formação continuada que possibilite o } \\
\text { aperfeiçoamento constante, a reflexão sobre a } \\
\text { prática pedagógica, formação esta realizada em } \\
\text { serviço como objetivo de compensar as } \\
\text { deficiências da formação inicial e manter o } \\
\text { docente atualizado com relação às tendências } \\
\text { pedagógicas atuais. }\end{array}$ & $\begin{array}{l}\text { - Mediante análise dos resultados obtidos na Avaliação } \\
\text { Institucional, o Coordenador Pedagógico deve estimular } \\
\text { a reflexão de suas práticas docentes e envolver os } \\
\text { professores em torno do projeto pedagógico. A reflexão } \\
\text { sobre os resultados da Avaliação Institucional deve } \\
\text { motivar a formação em exercício em busca do } \\
\text { aprimoramento de sua prática. } \\
\text { - O Coordenador Pedagógico deve motivar o grupo de } \\
\text { professores a buscar, em consenso, novas alternativas de } \\
\text { ensino, adequando à realidade da demanda específica } \\
\text { daquela unidade escolar; analisar suas características e } \\
\text { necessidades, fazendo-os entender que não há receitas } \\
\text { prontas na educação. Nesse sentido a formação } \\
\text { continuada perpassa pela troca de experiências. } \\
\text { - A escolha do Projeto Especial de Ação (PÁG.E.A) que } \\
\text { é realizada a cada ano deve seguir todas as orientações } \\
\text { descritas no projeto político-pedagógico, e a reflexão } \\
\text { periódica dos resultados que estão sendo, ou não, } \\
\text { atingidos com as mudanças das práticas pedagógicas } \\
\text { também deve fazer parte das pautas de formação. }\end{array}$ \\
\hline
\end{tabular}




\section{(II) O papel do coordenador pedagógico na formação continuada}

O Coordenador Pedagógico deve:

-“criar um ambiente" propício à discussão e encontros que possam progressivamente promover a formação continuada dos professores;

- promover a articulação dos diversos aspectos do projeto político-pedagógico da escola e exercer lembrar-se que seu trabalho é fundamentalmente um trabalho de formação continuada em serviço;

- exercer uma tarefa formadora, articuladora e transformadora, sendo necessário criar soluções adequadas a cada realidade.
O Coordenador Pedagógico deve:

- ter clareza de que está inserido no processo de formação continuada, formando e sendo formado. Portanto, para atender tal demanda, o C.PÁG. deve manter-se atualizado, realizando leituras especificas da sua área de atuação bem como a respeito de assuntos das diversas disciplinas e/ou segmentos;

- desempenhar um papel importante como formador do grupo de professores;

- elaborar as pautas de formação para os encontros semanais considerando as Orientações de SME / DOT, o Projeto Pedagógico e as metas da Unidade Escolar;

- elaborar um Plano de Formação dos Professores visando aprimorar os seus conhecimentos a fim de promover situações de aprendizagens realmente significativas. Esse plano deve estar em consonância com o documento "Orientações Curriculares e Expectativas de Aprendizagem" da Secretaria Municipal de Educação (SME/PMSP) a fim de implementá-lo.

\section{(III) Obstáculos encontrados para desempenhar sua função - com vistas ao papel de formador}

(a) vencer a resistência dos professores.

(b) trabalho burocrático e disciplinador que o afasta das verdadeiras funções de coordenação pedagógica.

(c) falta de tempo previsto na jornada de trabalho que permita encontros de estudos e discussões.

(d) falta de formação adequada do coordenador para ser formador de professores e/ou falta de assessoria para realizar esse tipo de trabalho.

(e) formação continuada baseada em seminários e palestras enfatizando a transmissão de informação teórica sem a preocupação em avaliar a prática dos professores em formação. (a) resistência dos professores.

(b) trabalho burocrático ocupando maior parte do tempo de trabalho.

(c) professores buscam "receitas" para utilizarem no processo de ensino, não vêem os horários pedagógicos como momentos de discussão, reflexão e construção coletiva.

(d) levar o docente a enxergar a Avaliação Institucional como indicador de aprimoramento.
Pode-se verificar no discurso das duas coordenadoras a valorização a atitude reflexiva da prática docente e, por conseguinte, incentivo à formação continuada, sempre com a consciência de que o Coordenador Pedagógico desempenha um papel importante nessa formação. As motivações para que a formação continuada ocorra são muito similares, embora o contexto em que elas ocorrem seja diferente, pois enquanto na rede pública há horário destinado para a reflexão sobre a prática docente (reuniões semanais) a rede particular, em sua maioria, não destina um tempo dentro do horário do professor para essa finalidade.

Os obstáculos encontrados pelas entrevistadas são bem semelhantes e devem inquietar a muitos outros Coordenadores Pedagógicos.

Motivados pelo panorama desenhado, quer pela LDB que ressoa as tendências sociais, quer pela pesquisa de campo que reforça aspectos já citados na LDB e amplia a temática em vários aspectos; propomos-nos a refletir sobre a formação docente, em particular a 
relevância da formação continuada, bem como analisar o papel da coordenação pedagógica na concretização do projeto educacional e na formação continuada do corpo docente.

\section{Formação Docente}

Com vistas às necessidades do mercado de trabalho, os professores (protagonistas do elenco de educadores na sociedade) têm em seu dia-a-dia a necessidade de elaborar julgamentos, os quais requerem a articulação entre seu conhecimento pessoal/profissional e sua prática. Este é "um processo que necessita de tempo. Um tempo para refazer identidades, para acomodar inovações, para assimilar mudanças" (NÓVOA, 1992, pág.16).

Não há lugar para uma formação dogmática, pelo contrário, a sociedade atual requer uma formação científica que é analítica e crítica. Estes dois aspectos da formação científica são essenciais para viabilizar uma qualidade no ensino e conseqüentemente nos cidadãos egressos do sistema escolar. No entanto, temos que ter claro em mente que não é possível formar professores sem fazer escolhas ideológicas (PERRENOUD, 2000). Conforme o modelo de sociedade e de ser humano que defendemos, não atribuiremos as mesmas finalidades à escola e, portanto, não definiremos da mesma maneira o papel dos professores.

As finalidades de um sistema educacional e as competências não podem ser dissociadas. O que será colocado em prática depende da visão política e dos recursos econômicos. Isso não nos impede de refletir sobre as competências desejáveis para um profissional atuar na escola de um futuro possível. É uma utopia necessária, no sentido de se definir aonde se quer chegar, o que um professor deveria saber, não para ensinar, mas para fazer aprender, não transmitir o saber, mas para construir competência e uma identidade, uma relação com o mundo e com o saber. As competências profissionais constroem-se em formação, ao sabor da navegação diária de um professor, de uma situação de trabalho à outra (LE BOTERF, 1997).

É natural que os profissionais se encontrem em crise de identidade frente ao rápido desenvolvimento científico e tecnológico, e com as mudanças significativas dos sistemas produtivos. Com os professores o processo não é diferente e esta crise de identidade é caracterizada, segundo Nóvoa, por três fases:

[...] a primeira distingue-se pela procura das características intrínsecas ao bom professor; a segunda define-se pela tentativa de encontrar o melhor método de ensino; a terceira caracterizase pela importância concedida à análise do ensino no contexto real de sala de aula, com base no c ham ado paradigma proces soproduto" (NÓVOA 1992, pág.14).

Analisaremos cada uma dessas fases mais detalhadamente.

\subsection{O professor e suas características}

Quando refletimos sobre as características de um professor, logo pensamos sobre a relação entre o saber e a prática; como o professor articula o saber de modo a torná-lo mais acessível ao aluno. Chevallard (apud FRANCHI, 2000; pág.16) ao falar sobre transposição didática, escreve:

\footnotetext{
Um conteúdo do conhecimento, tendo sido designado como saber a ensinar, sofre então um conjunto de transformações adaptativas que vão torná-lo apto a tomar lugar entre os 'objetos de ensino'. O 'trabalho', que de um objeto de saber a ensinar faz um objeto de ensino, é chamado de transposição didática. (pág.39)
}

Nessa perspectiva Tardif busca relacionar a questão dos saberes com a prática dos docentes. Inicialmente ele ressalta a importância de considerar os professores como sujeitos que possuem, utilizam e produzem saberes específicos ao seu oficio e ao seu trabalho. Nesse sentido, Tardif (2002, pág.36) afirma que [...]."'interessar-se pelos saberes e pela subjetividade deles é tentar penetrar no próprio cerne do processo concreto de escolarização, tal como ele se realiza a partir 
do trabalho cotidiano dos professores em interação com os alunos e com outros atores educacionais".

Tardif ressalta que é incontestável que enquanto grupo social, e em virtude das próprias funções que exercem, os professores ocupam uma posição estratégica no interior das relações que unem as sociedades contemporâneas aos saberes que elas produzem e mobilizam com diversos fins e que a relação dos professores com os saberes não se reduz a uma função de transmissão dos conhecimentos já constituídos. Sua prática integra diferentes saberes, com os quais o corpo docente mantém diferentes relações. Propõe a seguinte definição do saber docente: "[...] é um saber plural, formado pelo amálgama, mais ou menos coerente, de saberes oriundos da formação profissional e de saberes disciplinares, curriculares e experienciais" (Ibid, pág.36).

\subsection{O processo de ensino-aprendizagem}

A busca por um método de ensino que minimize os obstáculos encontrados no processo de ensino aprendizagem, como já dissemos, é uma constante preocupação do professor. O professor, profissional da educação, deve desenvolver as competências necessárias e intrínsecas ao seu ofício, essas "[...] competências profissionais, constroem-se em formação, ao sabor da navegação diária de um professor, de uma situação de trabalho à outra" (LE BOTERF, 1997 apud PERRENOUD, 2000, pág.15).

A idéia de competência não é nova, mas seu uso está sendo difundido no atual contexto político social, dando-lhe conotações de inovação, com repercussões que vêm demarcando novas posturas dos educadores que atuam, tanto no âmbito da formação profissional mais específica, quanto no âmbito educacional da formação básica. Tal conceito existe em vários países com tendência a orientar o currículo para a construção de competências desde a escola fundamental (PERRENOUD, 1998).

A noção de competência nos trabalhos de Philippe Perrenoud designará uma capacidade de mobilizar diversos recursos cognitivos para enfrentar um tipo de situações. As competências integram, mobilizam saberes, savoir faire ${ }^{2}$ ou atitudes que são pertinentes em situações de aprendizagem.

O exercício da competência passa por operações mentais complexas, esquemas de pensamento (PERRENOUD, 2001). A natureza dos esquemas de pensamento é que permitem a mobilização dos recursos pertinentes em situação.

Perrenoud (2000) tem como objetivo analisar o funcionamento das competências, a fim de fazer um inventário dos conhecimentos teóricos e metodológicos que elas mobilizam. Apresentamos os dez domínios de competências para ensinar bem numa sociedade em que o conhecimento está cada vez mais acessível.

Descreveremos algumas competências citadas por Perrenoud, discorrendo sobre as que julgarmos mais interessantes, sem a intenção de esgotar o assunto e nem tão pouco citar e/ou descrever todas as competências, mesmo que isto fosse possível. São elas:

1. Organizar e dirigir situações de aprendizagem

O ofício de professor "[...] hoje precisa conceber uma postura de conceptores dirigentes d e situaçõ es d e aprendizagem" (PERRENOUD, 2000, pág.23).

A busca de um ensino interativo, possibilitando vivências para os alunos, faz parte da prática do professor. $\mathrm{O}$ modelo de ensino precisa ser centrado no aluno, para que oportunidades de intervenções individuais aconteçam na rotina da sala de aula. 
Para organizar e dirigir situações de aprendizagem, é necessário dispor das competências profissionais necessárias, para imaginar e criar outros tipos de situações de aprendizagens amplas, abertas e carregadas de sentido e de regulação.

A verdadeira competência pedagógica não está centrada apenas em reconhecer bem os conteúdos a serem ensinados, mas em os relacionar a objetivos e a situações de aprendizagem. Essa habilidade na administração das situações e dos contextos exige um domínio que Develay (1992) chama de matriz disciplinar. São os conceitos e os paradigmas que estruturam os saberes no seio de uma disciplina.

Trabalhar a partir das representações dos alunos exige uma competência essencialmente didática. O professor precisa entender o que o aluno pensa, como pensa e por que pensa daquela maneira. Na prática da sala de aula, abrir espaços para discussões e negociações de idéias.

Bachelard (1996) observa que os professores têm dificuldades para compreender que seus alunos não compreendem, já que não se lembram do caminho do conhecimento, dos obstáculos, das incertezas, dos atalhos, dos momentos de vazio pelos quais passaram quando eram estudantes.

Entretanto, para Perrenoud (2000), não basta que os professores tenham memórias de suas próprias aprendizagens, é necessário buscar uma cultura mais extensa em história da matemática, em filosofia das ciências, em antropologia, em psicologia genética e em psicologia da aprendizagem.

2. Administrar a progressão das aprendizagens

A escola é organizada para favorecer a progressão das aprendizagens dos alunos ao final de cada ciclo de estudos. Todo o ensino deveria ser estratégico, no sentido dado por Tardif (1992), concebido em uma perspectiva a longo prazo, cada ação sendo decidida em função de sua contribuição almejada à progressão ótima das aprendizagens de cada um.

Com a introdução de ciclos de aprendizagem plurianuais, o movimento rumo à individualização dos percursos de formação $\mathrm{e}$ à pedagogia diferenciada leva a que se pense na progressão de cada aluno.

3. Conceber e fazer evoluir os dispositivos de diferenciação

Diferenciar é romper com a pedagogia frontal, a mesma lição para todos, os mesmos exercícios para todos, mas é criar uma organização do trabalho e dos dispositivos didáticos que coloque cada um dos alunos em uma situação ótima, priorizando aqueles que têm mais a aprender.

4. Envolver os alunos em suas aprendizagens e em seu trabalho

A competência e a vontade de desenvolver o desejo de saber e a decisão de aprender encontram-se no centro do ofício de professor.

A competência profissional de desenvolver esse desejo apela para dois recursos:

a) compreensão e um certo domínio dos fatores e mecanismos sociológicos, didáticos e psicológicos em jogo no surgimento e na manutenção do desejo de saber e da decisão de aprender;

b) habilidade no campo da transposição didática, das situações, das competências, do trabalho sobre a transferência dos conhecimentos. Identificar os projetos pessoais existentes, sob todas as suas forças, valorizálos e reforçá-los.

\section{Trabalhar em equipe}

A evolução da escola caminha para a cooperação profissional. A divisão do trabalho pedagógico aumenta na escola básica. Isso suscita novas formas de cooperação: a repartição igualitária das tarefas.

As competências específicas para o trabalho em equipe são: saber trabalhar eficazmente em equipe, saber discernir os problemas que 
requerem uma cooperação intensiva. Saber é perceber, analisar e combater resistências e impasses ligados à cooperação. É saber se autoavaliar.

\section{Participar da administração da escola}

O modo de gestão da escola permanece arcaico, burocrático, baseado mais na desconfiança, na liberdade clandestina do que na autonomia assumida, na aparência do controle do que na transparência das escolhas e na obrigação de prestar contas. Profissionalização, responsabilização, participação, autonomia de gestão, projetos da instituição e cooperação designam alternativas desejáveis para um funcionamento da escola.

Uma nova organização em ciclos de aprendizagem modifica o equilíbrio entre responsabilidades individuais e responsabilidades coletivas e torna necessário, não somente um trabalho em equipe, mas também uma cooperação da totalidade do estabelecimento, de preferência baseada em um projeto (CHARLIER e PERRENOUD, 1996).

\section{Utilizar novas tecnologias}

A escola não pode ignorar o que se passa no mundo. As novas tecnologias da informação e da comunicação transformam não só nossas maneiras de comunicar, mas também de trabalhar, de decidir, de pensar.

\section{Administrar sua própria formação contínua}

Pode-se ver, com as competências destacadas anteriormente, que Perrenoud foi bastante detalhista e evidenciou as principais características que devem estar presentes em um professor, mas certamente poderíamos transpor as fronteiras escolares e transferirmos muitas destas competências aos profissionais que a sociedade espera formar, seja qual for a área de atuação.

Mas detendo-nos ao ofício de professor, fazse necessário analisar este profissional em seu ambiente de trabalho: a sala de aula. É neste ambiente que se dá o processo de ensinoaprendizagem, onde o saber é construído pelo aluno com a orientação e auxílio da transposição do saber realizada pelo professor.

\subsection{O professor e a sala de aula}

A construção do conhecimento é uma trajetória coletiva que o professor orienta, criando situações e dando auxílio, sem ser o especialista que transmite o saber, nem o guia que propõe a solução para o problema. Devemse conceber situações que estimulem o conflito cognitivo entre alunos ou na mente de cada um.

Trabalhar a partir dos erros e dos obstáculos de aprendizagem é uma competência que se baseia no princípio de que o aprender está na reestruturação do sistema de compreensão de mundo, não em estocar informações, nem em só memorizar. Uma verdadeira situaçãoproblema obriga a transpor um obstáculo, quer se trate de uma simples transferência, de uma generalização ou da construção de um conhecimento inteiramente novo. Os obstáculos cognitivos são constituídos por falhas de raciocínio, pistas falsas, erros de estimativa ou de cálculo.

O obstáculo, conforme expressão de Martinand (1986) torna-se, então, o objetivo do momento. Deparar-se com o obstáculo é enfrentar a ausência de qualquer solução num primeiro momento, até mesmo de qualquer pista, e uma sensação de que não se vai conseguir encontrar a solução. Os alunos se envolvem no problema, interagem, constroem hipóteses e propõem alternativas. Em um trabalho coletivo, socializa-se a discussão. $\mathrm{O}$ choque das representações obriga cada um a rever seu pensamento e a levar em conta o dos outros.

A didática das disciplinas interessa-se cada vez mais pelos erros e tenta compreendê-los. Astolfi (1997) propõe considerar o erro como uma ferramenta para ensinar, um revelador dos mecanismos de aprendizagem do aluno. 
Dispositivos e seqüências didáticas buscam fazer com que se aprenda a mobilizar os alunos seja para compreenderem, seja para terem êxito. Se possível, os dois (PIAGET, 1974).

Todo dispositivo repousa sobre hipóteses relativas à aprendizagem e à relação com o saber, o projeto, a ação, a cooperação, o erro, a incerteza, com o êxito e o fracasso, com o obstáculo, com o tempo.

\section{A Coordenação Pedagógica - projeto educacional e formação de professores}

Difícil refletir a respeito dos desafios postos à escola nos dias atuais e não se lembrar dos atores envolvidos: coordenação pedagógica e professores. Cada qual desempenha um papel importante e imprescindível no processo educacional, porém, é inegável que para se ter um projeto educacional exeqüível faz-se necessário envolver esses atores em ações que mobilizem habilidades e competências educacionais com foco em dirimir fraquezas e superar obstáculos, quer sejam de ordem coletiva ou individual.

Dessa maneira, buscaremos analisar aspectos ligados à atuação da Coordenação Pedagógica, nossa intenção não é esgotá-los, mas apresentar pontos mais relevantes $\mathrm{e}$ destacar aspectos ligados à condução do projeto pedagógico e cooperação à formação continuada do corpo docente.

Explanaremos a respeito de cada um desses itens mais detalhadamente.

\subsection{Coordenação Pedagógica como} liderança

É impossível não visualizar a Coordenação Pedagógica como uma função de liderança intrínseca. Ao perceber que a Coordenação Pedagógica deve como liderança, “[...] influenciar um processo de inovação de múltiplas maneiras e em diversas fases do ciclo da vida de um projeto" (THURLER, 2001, pág. 142), projeto este, construído com a comunidade educativa.

Vemos que a liderança é ativa, deve-se ter consciência de que tem inicio na construção do projeto e estende-se durante todo o processo de execução, ela "influencia a orientação do projeto, a formulação dos objetivos, o justo equilíbrio entre utopia e realismo" [...] exerce sua influencia durante a aplicação do projeto coletivo, especialmente quando ele tropeça em algum obstáculo, em um dilema ou em um problema tático ou estratégico" (ibid., pág. 142). Diante disso, pode-se evidenciar que a influencia do Coordenador Pedagógico é de grande valia e essencial para propiciar a formação de um grupo docente coeso e que trabalha com metas claras.

As discussões sobre a importância do projeto-político pedagógico, sobre a valorização das ações coletivas, vinculadas ao eixo pedagógico desenvolvido na escola e a atuação do coordenador como gestor do trabalho que oferece feedback, aquele que "apresenta os objetivos de maneira a provocar o engajamento da maioria, cria um clima de tentativa coletiva, de resolução de problemas e de aprendizagem permanente" (THURLER, 2001, pág.147); contribui para a constituição de um grupo de professores engajados com a proposta pedagógica, com os projetos desenvolvidos (idealizados e traçados em processo colaborativo).

4.2. O papel do projeto políticopedagógico na escola - sua interferência nas atribuições do coordenador pedagógico

Inicialmente devemos nos perguntar o que é o projeto político-pedagógico. Dizemos que tem caráter político porque diz respeito à organização, a governabilidade da escola; ele prevê e dá uma direção à gestão da escola. Já o caráter pedagógico faz-se presente nas 
reflexões sistemáticas sobre as práticas educativas: dá sentido e rumo às práticas educativas, contextualizadas culturalmente.

Viabiliza a participação coletiva e reflexiva dos atuantes da vida escolar (professores, diretores, coordenadores). É a construção do projeto político-pedagógico que dará as diretrizes para a atuação do trabalho da coordenação pedagógica, uma vez que, sua função será viabilizar o trabalho do professor, oferecendo condições à realização das atividades pedagógicas, o que, sem dúvida, reflete na dinâmica da sala de aula. As escolhas realizadas pela coordenação pedagógica a fim de implementação de gestões educativas, perpassando pelas prioridades dos recursos financeiros, deverão ser realizadas em consonância com o que o projeto políticopedagógico norteia.

Sendo assim, cabe reforçar que o projeto político-pedagógico representa a “[...] oportunidade de a direção, a coordenação pedagógica, os professores e a comunidade, tomarem sua escola nas mãos, definir seu papel estratégico na educação das crianças e jovens, organizar suas ações, visando a atingir os objetivos que se propõem" (LIBÂNEO, TOSCHI e OLIVEIRA; 2003, pág. 125).

Toda escola possui algum projeto pedagógico, seja ele formalizado em um texto ou vivido no dia-a-dia da sala de aula. A formalização e institucionalização desse projeto (político-pedagógico) auxiliam na solução de questões fundamentais para vida escolar, na construção da identidade da escola e na diretriz de suas ações, viabilizando que a escola se estruture e busque alcançar as metas traçadas coletiva e participativamente.

\subsection{Coordenação Pedagógica -} participação na formação continuada

Há também o aspecto de contribuir na formação contínua do professor. Sem dúvida é uma área importante de atuação da
Coordenação Pedagógica, pois é no seu fazer diário que a coordenação evidencia e ratifica a importância da formação continuada. É nos momentos que "[...] se reúnem para discutir questões e problemas pedagógicos, isto é, pertinentes à sala de aula, ao conteúdo de ensino, ao desempenho dos educandos e ao relacionamento com os alunos" (GEGLIO, 2006, pág.117) que se está contribuindo para a formação docente.

Não se pode olvidar que, conhecedor das necessidades dos educandos e orquestrador das ações necessárias para soluções de problemas levantados pelos docentes (didáticopedagógicos, disciplinares ou de outra natureza), o coordenador pedagógico deve planejar a maneira que conduzirá os encontros coletivos (selecionando as leituras e mediando os debates), pois ele "deve ter observado as necessidades dos professores, na relação com os alunos, com o ensino, com a visão de educação, com a concepção de aprendizagem e avaliação" (SOUZA, 2005, pág.28). Como se pode notar, o trabalho coletivo é parte integrante dessa formação, uma vez que viabiliza a troca de experiências e a reflexão da prática docente (CHRISTOV, 2005). Reiteramos que esses momentos de trabalho coletivo acrescentam muito à formação do professor, dado que o saber docente é plural e um amalgama dos saberes profissionais e de saberes disciplinares, curriculares e experienciais (TARDIF, 2002).

$\mathrm{O}$ coordenador deve atentar às necessidades especificas de seus liderados e, portanto, empreender em seu planejamento momentos em que, intencionalmente, aborde as fraquezas dos componentes do grupo e do coletivo. O coordenador pedagógico deve auxiliar os professores na descoberta e construção de habilidades e competências imprescindíveis à sua atuação como educador, e, portanto, é necessário que indique ou traga aos seus liderados meios para essa qualificação, ou ainda que se valha de meios próprios (atuando como formador em um processo de 
qualificação). Corrobora com esses aspectos citados a necessidade de que o professor tenha elementos para analisar sua própria pratica à luz das contribuições dos pensadores da educação (CHRISTOV, 2005).

\subsection{Reflexão sobre sua prática}

E por último, mas não menos importante a reflexão sobre a metodologia de trabalho do coordenador, a qual deve envolver: ação $\rightarrow$ reflexão $\rightarrow$ ação. É um processo continuo e dialético, uma vez que após cada ação praticada requer que se faça uma reflexão sobre as metas alcançadas, eficácia dos procedimentos e posterior ação corretiva do que pôde causar desvio e, consequentemente, comprometer as metas traçadas, ou seja, impedindo que as mesmas sejam alcançadas satisfatoriamente. Libâneo (2003) corrobora com essa necessidade de reflexão quando afirma que:

[...] para enfrentar as mudanças, a ação e a reflexão atuam simultameamente, porque elas estão sempre entrelaçadas. Podemos refletir nossa ação, transformando nossa ação em pensamento. Ao mesmo tempo, podemos traduzir idéias em ações. Propõe-se, assim, uma formação profissional - tanto a inicial como a continuada baseada na articulação entre a prática e a reflexão sobre a prática, de modo que o professor vá se transformando em um profissional crítico e reflexivo, isto é, um profissional que domina uma prática refletida (pág.28).

Mas para que as ações surtam resultados significativos, condizentes com a realidade de trabalho e propicie a concretização das metas traçadas no projeto político-pedagógico, é imprescindível que o coordenador pedagógico esteja inteirado do conhecimento e da experiência pedagógica dos professores. É necessário criar uma metodologia de trabalho que possibilite aos professores e a si próprio atuarem como protagonistas, sujeitos ativos no processo de identificação, análise e reflexão dos problemas existentes na escola e na elaboração de propostas para sua superação. Lembrando de estabelecer prioridades de plano de ação a curto, médio e longo prazo.
Portanto o coordenador pedagógico deve: (a) buscar compreender a realidade da escola em que atua - conhecer o corpo discente e docente, a comunidade e direção (b) identificar os problemas prementes - analisar e investigar suas raízes (origem) e causas; envolver o corpo docente na reflexão crítica e (c) criar metodologia para o trabalho - elaborar propostas a fim de solucionar, ou quiçá minimizar, os problemas levantados. Cabe ao coordenador valorizar as experiências, projetos positivos em desenvolvimento na escola e compartilhar com todos, estimulando a participação dos docentes e, por valer-se das experiências positivas, criar outros projetos que auxiliam alcançar as metas estabelecidas em conjunto.

O coordenador pedagógico deve olhar a escola a partir de seus professores, alunos e suas condições materiais; tomar conhecimento dos índices de evasão/repetência; localizar as principais questões de ensino e aprendizagem; inteirar-se de como está organizado os trabalhos dos professores. Nos momentos de trabalho coletivo direcionar discussões que viabilizem refletir sobre a prática docente, sobre processos de avaliação e teorias de aprendizagem.

\section{Considerações Finais}

Vimos que a reflexão sobre a formação de professores e sobre a escolha (ideológica) de qual escola se quer e, então, qual sistema educacional se adotará, é o único caminho possível para educar cidadãos atuantes e valorosos à sociedade moderna.

Cabe ao professor refletir sobre seu importante papel nesta sociedade e, motivados por sua atuação na construção da sociedade, construir as competências necessárias para tornar-se um agente transformador.

O dia-a-dia do ambiente escolar e o processo de ensino-aprendizagem envolvem a presença de indivíduos que ensinam e 
aprendem ao mesmo tempo, assim sendo a escola é vista como uma organização que possui fins políticos, ideológicos e culturais na qual os indivíduos e grupos (corpo diretivo, corpo docente e discente) mobilizam poderes e elaboram processos de negociações, pactos e enfrentamentos. Com a finalidade e intencionalidade de viabilizar meios pelos quais a escola possa atingir suas finalidades e objetivos, traçados no projeto políticopedagógico, construído, em conjunto pelos principais atores do processo; faz-se necessário que a escola determine papéis e responsabilidades, juntamente com o relacionamento entre os vários setores que determina o sistema educacional.

Cabe a Coordenação Pedagógica a incumbência, difícil e ao mesmo tempo essencial, de coordenar, acompanhar, assessorar, apoiar e avaliar as atividades pedagógicas, sempre norteadas pela função prioritária que é prestar assistência pedagógica e didática aos professores em suas respectivas disciplinas. Outra função importante da coordenação é estabelecer um relacionamento com os pais e com a comunidade, buscando sempre o maior ideal que é a aprendizagem do educando, visando suprir suas necessidades e buscando um engrandecimento pessoal, com responsabilidades, respeito, dignidade e apto a fazer parte de uma sociedade sem frustrações e preconceito.

A Coordenação Pedagógica deve como liderança "influenciar um processo de inovação de múltiplas maneiras e em diversas fases do ciclo da vida de um projeto" (THURLER, 2001, pág.142), projeto este, como já foi dito, construído com a comunidade educativa. Seu papel inicia na construção do projeto e estende- se durante todo o processo de execução, ela "influencia a orientação do projeto, a formulação dos objetivos, o justo equilíbrio entre utopia e realismo [...] exerce sua influencia durante a aplicação do projeto coletivo, especialmente quando ele tropeça em algum obstáculo, em um dilema ou em um problema tático ou estratégico" (ibid, pág.142).

Pode-se ver que tal atuação tem influencia significativa na constituição e atuação do grupo de professores, uma vez que, o tom que a coordenação dá ao trabalho pode vir a estimular ou a cercear a participação dos professores e dos lideres constituídos. A coordenação pedagógica deve ter em mente a necessidade de ter papel conciliador e integrador, uma vez que suas ações podem "mobilizar e canalizar o engajamento de todos no sentido da mudança, como podem tornar-se freios, ou mesmo adversários declarados do projeto" (ibidem, pág.146).

A atuação da coordenação como conciliador de conflitos, como gestor do trabalho que oferece feedback, aquele que "apresenta os objetivos de maneira a provocar o engajamento da maioria, cria um clima de tentativa coletiva, de resolução de problemas e de aprendizagem permanente" (ibidem, pág.147); contribui para a constituição de um grupo de professores engajados com a proposta pedagógica, com os projetos desenvolvidos (idealizados e traçados em processo colaborativo).

Desempenhando com diligência e compromisso seus papéis, coordenação pedagógica e corpo docente atuarão de forma orquestrada na formação de cidadãos aptos a coletar informações de diversas fontes e analisá-las de forma crítica e eficaz.

\section{Referências Bibliográficas}

ASTOLFI J. PÁG. L'erreur, un outil pour enseigner. Paris: ESF éditeur, 1997.

BACHELARD, G. A formação do espírito científico: contribuição para uma psicanálise do conhecimento. Rio de Janeiro: Contraponto, 1996. 
BRASIL, Governo. Leis de Diretrizes e Bases da Educação Nacional no 9394/96. Disponível em: $<$ portal.mec.gov.br/secad/arquivos/pdf/ldb.pdf> Acesso em: 30 jun. 2010 às 14h.

CHARLIER E.; PERRENOUD, Pág.(Org.). Former des enseignants professionnels. Quelles strátegies? Quelles compétences? Bruxelas: De Boeck, ppág. 181-208, 1996.

CHEVALLARD, Y. La transposition didactique: du savoir savant au savoir enseigné. Grenoble, La Pensée Sauvage, 1991.

CHRISTOV, L.H. da S. Intenções e problemas em prática de coordenação pedagógica. In: PLACO, V.M.N. de S e ALMEIDA, L.R. O coordenador pedagógico e o espaço de mudança. S.PÁG., Loyola, 2005, p. 35-43.

DEVELAY M. De L'apprentissage à l'enseignement. Paris: ESF éditeur, 1992.

FRANCHI, A. et al. Educação Matemática: uma introdução. EDUC, 2000.

GEGLIO, PÁG.C. O papel do coordenador pedagógico na formação do professor em serviço. In: PLACO, V.M.N. de S e ALMEIDA, L.R. O coordenador pedagógico e o cotidiano da escola S.PÁG., Loyola, 2006, p.113-119.

LE BOTERF, G. De la compétence à la navigation professionnelle. Paris: Les Éditions d'Organisation, 1997.

LIBÂNEO, J. C.; TOSCHI, M. S.; OLIVEIRA, J. F. de. Educação Escolar: políticas, estrutura e organização. São Paulo: Cortez, 2003.

MARTINAND, J.L. Connaître et transformer la matière. Berna: Lang, 1986.

NÓVOA, A. (org). Formação de Professores e Profissão docente. In: Nóvoa. Os professores e a sua formação. Lisboa, Portugal, D.Quixote, 1992 (Temas da Educação/1).

PERRENOUD, PÁG. Construire des competénces des l'école - 2ème ed. Paris: ESF éditeur, 1998.

Dez novas competências para ensinar. Trad. Patrícia Chittoni Ramos. Porto Alegre: Artes Médicas Sul, 2000.

PERRENOUD, PÁG. et al. Formando professores profissionais. Porto Alegre: Artes Médicas Sul, 2001.

PIAGET, Jean. A Epistemologia Genética e a Pesquisa Psicológica. Rio de Janeiro: Freitas Bastos, 1974.

SILVA, H. PÁG. da et al. Inclusão digital e educação para a competência informacional: uma questão de ética e cidadania. Revista IBICT, vol. 34, n. 1, 2005 - Disponível em: <http:// revista.ibict.br/index.php/ciinf/article/viewArticle/611>. Acesso em: 22 jul. 2010.

SOUZA, V.L.T.de. O coordenador pedagógico e a constituição do grupo de professores - In: PLACO, V.M.N. de S e ALMEIDA, L.R. O coordenador pedagógico e o espaço de mudança. S.PÁG., Loyola, 2005, pág.27-34.

TARDIF, J. Pour un enseignement stratégique: L'apport de la psychologie cognitive. Montréal: Éditions Logiques, 1992.

. Saberes Docentes e Formação Profissional. Petrópolis, RJ. Vozes, 2002.

THURLER, M. G. Inovar no Interior da Escola. trad. Jeni Wolff - Porto Alegre, Ed. Artmed, 2001 